\title{
Correction to: A Comparison of Measurements of a Pediatric Supplement
}

Taylor N. Creech ${ }^{1}$ (D) - Michael Bailey-Van Kuren ${ }^{2} \cdot$ Jessica Sparks ${ }^{3} \cdot$ Samantha B. Becker $^{1}$. Rita S. N. Kou ${ }^{1} \cdot$ Olivia C. Wnek $^{1} \cdot$ Donna R. Scarborough ${ }^{1}$

Published online: 14 September 2018

(C) Springer Science+Business Media, LLC, part of Springer Nature 2018

\section{Correction to: Dysphagia}

https://doi.org/10.1007/s00455-018-9931-6

The original version of this article unfortunately contained mistakes.

1. The "Reproduced permission" text was added at the Figure 2 caption mistakenly. Hence, the Figure 2 and caption has been corrected with this correction.

2. The subheading "IDDSI Procedures" should be updated as "Flow Rate Procedures" under the "Methods" section.

The original article can be found online at https:// doi.org/10.1007/s00455-018-9931-6.

Donna R. Scarborough

scarbod@miamioh.edu

Taylor N. Creech

creechtn@miamioh.edu

Michael Bailey-Van Kuren

baileym@miamioh.edu

Jessica Sparks

sparksj6@miamioh.edu

1 Department of Speech Pathology and Audiology, Miami University, 301 S. Patterson Dr, 26 Bachelor Hall, Oxford, OH 45056, USA

2 Department of Mechanical and Manufacturing Engineering, Miami University, Oxford, OH, USA

3 Department of Chemical, Paper, and Biomedical Engineering, Miami University, Oxford, OH, USA
Taylor N. Creech MA, BA

Michael Bailey-Van Kuren PhD, MS, BS

Jessica Sparks PhD, MS, BS

Samantha B. Becker BS

Rita S. N. Kou BS

Olivia C. Wnek BS

Donna R. Scarborough $\mathrm{PhD}$, MS, BS 
Fig. 2 The National Dysphagia Diet Task Force defines viscosity in standardized viscosity measurements in centipoise $(\mathrm{cP})$ with strict class boundaries at a shear rate $\left(\mathrm{s}^{-1}\right)$ of $50 \mathrm{~s}^{-1}[13,18]$. The

International Dysphagia Diet

Standardization Initiative utilizes flow rate as an indicator for liquid level; the scale of $0-4$ is determined by the amount of liquid remaining in a $10 \mathrm{~mL}$ syringe following a free flow period of $10 \mathrm{~s}$ [19]

\begin{tabular}{|l|}
\hline \multicolumn{1}{|c|}{ NDD Liquid Levels } \\
\hline Thin: $1-50 \mathrm{cP}$ \\
\hline Nectar: $51-350 \mathrm{cP}$ \\
\hline Honey: $351-1750 \mathrm{cP}$ \\
\hline Spoon Thick: $1750+\mathrm{cP}$ \\
\hline
\end{tabular}

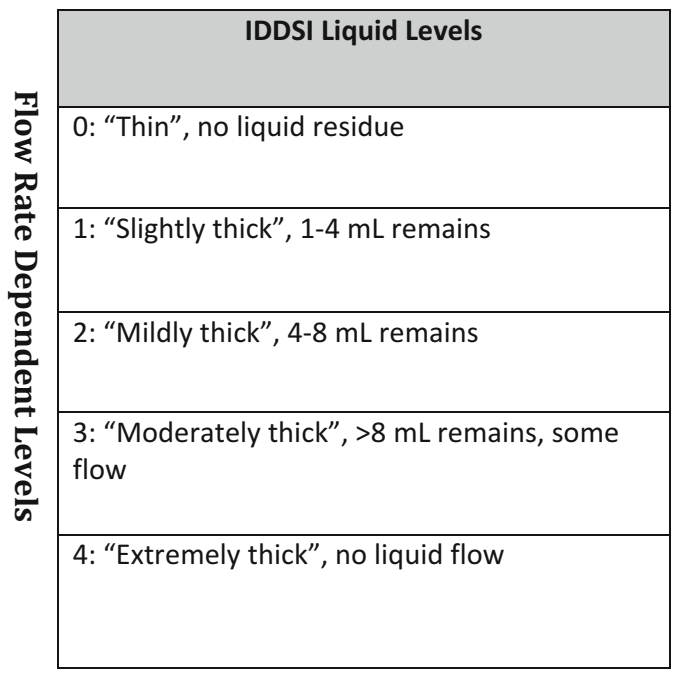

